\title{
Advancing the Technology R\&D of Tabletop Mesoscale Nondestructive Characterization
}

H. E. Martz, Jr., M. Aufderheide, A. Barty, J. A. Jackson, J. S. Kallman, B. Kozioziemski, W. Nederbragt, M. Pivovaroff, D. Schneberk

October 15, 2004 
This document was prepared as an account of work sponsored by an agency of the United States Government. Neither the United States Government nor the University of California nor any of their employees, makes any warranty, express or implied, or assumes any legal liability or responsibility for the accuracy, completeness, or usefulness of any information, apparatus, product, or process disclosed, or represents that its use would not infringe privately owned rights. Reference herein to any specific commercial product, process, or service by trade name, trademark, manufacturer, or otherwise, does not necessarily constitute or imply its endorsement, recommendation, or favoring by the United States Government or the University of California. The views and opinions of authors expressed herein do not necessarily state or reflect those of the United States Government or the University of California, and shall not be used for advertising or product endorsement purposes.

This work was performed under the auspices of the U.S. Department of Energy by University of California, Lawrence Livermore National Laboratory under Contract W-7405-Eng-48. 


\section{Advancing the Technology R\&D of Tabletop Mesoscale Nondestructive Characterization ${ }^{1}$}

Harry E. Martz, Jr., Engineering, Maurice Aufderheide, Defense and Nuclear Technology, Anton Barty, Physics \& Advanced Technologies, Jessie A. Jackson, Engineering, Jeffrey S. Kallman, Engineering, Bernard Kozioziemski, Inertial Confinement Fusion, Walter Nederbragt, Engineering, Michael Pivovaroff, Physics \& Advanced Technologies, and Daniel Schneberk, Computations

UCRL-TR-207261, Lawrence Livermore National Laboratory, Livermore, CA 94550

\section{Project overview}

This Strategic Initiative (SI) will advance nondestructive characterization of mesoscale (millimeter-sized) objects - allowing micrometer resolution over the objects' entire volume. Xray imaging will be developed that allows object characterization with materials that vary widely in composition, density, and geometry.[Martz and Albrecht, 2004]

\section{Project goals}

The overall goal is to research the science and engineering needed to nondestructively characterize and model mesoscale objects. The spatial resolution goal for this microscopy is roughly one cubic micrometer or better, while the contrast goal represents a signal-tonoise ratio of 1000:1.

\section{Relevance to the lab Mission}

This SI will enable the science and technology of phase- and amplitude-contrast modeling and object recovery. Specific LLNL programs that would benefit include development of novel sensors for NAI applications, study of explosive samples for DOD and DOE, high energy density physics, and inertial confinement fusion (ICF) experiments for the National Ignition Facility (NIF).

\section{FY04 Accomplishments and Results}

We performed several types of modeling to better understand $\mathrm{x}$-ray imaging of mesoscale objects. Characterization of the solid deuterium-tritium (D-T) fuel layer in an ICF capsule using a beryllium ablator requires phase-contrast imaging. We chose this as one example for our modeling work. We modeled projection imaging systems with a coherent parallelbeam and a point source, and a large-size source with a Wolter x-ray imaging optic (Figure 1). These studies showed that imaging was possible with either approach [Barty, et al. 2004]

Objects with geometric and x-ray properties comparable to an ICF capsule were used in initial experimental tests of the modeling results. These objects were successfully imaged using LLNL's KCAT system, Xradia's uXCT, and ANL's Advanced Photon Source [Kozioziemski, et al. 2004]. Due to the stopping of the SI proegrammatic funds and KCAT were used to successfully image both a D-T liquid/gas and solid/gas layer inside a beryllium capsule.

\footnotetext{
${ }^{1}$ This work was performed under the auspices of the U.S. Department of Energy by the University of California, Lawrence Livermore National Laboratory under Contract No. W-7405-Eng-48.
} 
We examined whether it is necessary to use the multislice method to solve the paraxial wave equation to simulate x-ray microscopy of mesoscale objects or if ray tracing will suffice. Preliminary results reveal ray tracing was adequate for modeling the propagation of x-rays through mesoscale objects of interest.[Kallman, 2004]

Additional modeling probed the imaging capability and limitations of a Wolter x-ray microscope system. This system was designed to characterize mesoscale objects to submicrometer spatial resolutions. [Nederbragt, 2002] A code has been developed to model the 2D image formation in a Wolter x-ray microscope.[Jackson, 2004] A series of simulations using various objects were run to study the effects of the optics, neglecting scattering and reflection losses (Figure 2). These simulations were analyzed using both laminographic and tomosynthesis methods (Figure 3).[Schneberk, et al., 2004]

One Wolter 8-keV x-ray optic was fabricated for the microscope. Unfortunately, the mandrel did not meet the required specifications.[see Taylor LDRD report] However, two important achievements resulted from the fabrication effort. First, the team developed a framework and methodology for the construction of high precision optics for future efforts at LLNL (Figure 4). The second achievement was the demonstration of both a laterallyand depth-graded multilayer coating to maximize the throughput of the optic (Figure 5).

\section{FY05 Proposed Work}

The SI was terminated and has evolved into two LDRD ERs. One focuses on x-ray phaseeffects characterization, [see Martz LDRD report] the other on x-ray optics fabrication [see Taylor LDRD report].

\section{Related References}

Barty, A., M. B. Aufdeheide, B. J. Kozioziemski, D. J. Schneberk and H. E. Martz, Jr. (2004), "Phase contrast induced errors in micrometer-scale precision x-ray metrology," to be submitted to J. of Nondestr. Eval., Lawrence Livermore National Laboratory, Livermore, CA, UCRL-

Jackson, J. A., (2004), "Wolter X-ray Microscope Computed Tomography Ray-Trace Model with Preliminary Simulation Results,” Lawrence Livermore National Laboratory, Livermore, CA, UCRL-TR-206864.

Kallman, J. (2004), “Is Multislice Necessary?” Lawrence Livermore National Laboratory, Livermore, CA, UCRL-TR-207667.

Kozioziemski, B.J., J.A. Koch, A. Barty, H. E. Martz, Wah-Kewat Lee and Kamel Fezzaa (2004), “Quantitative Characterization of Inertial Confinement Fusion Capsules Using Phase Contrast Enhanced X-Ray Imaging”, submitted to J. Appl. Phys., Lawrence Livermore National Laboratory, Livermore, CA, UCRL-JRNL-205025.

Martz, Jr., Harry E., Maurice Aufderheide, Anton Barty, Jessie A. Jackson, Jeffrey S. Kallman, Bernard Kozioziemski, Walter Nederbragt, Michael Pivovaroff, and Daniel Schneberk, "Advancing the R\&D of Mesoscale Nondestructive Characterization," Lawrence Livermore National Laboratory, Livermore, Calif., UCRL-TR207264, October 2004.

Martz Jr., H. E., and G. F. Albrecht, (2003), "Nondestructive Characterization Technologies for Metrology of Micro/Mesoscale Assemblies," Proceedings of: Machines and Processes for Micro-scale and Meso-scale Fabrication, Metrology, and Assembly, ASPE 2003 Winter Topical Meeting, Gainesville, FL, January 22-23, pp.131-141.

Nederbragt, W. (2002), “Wölter Instrument-Optical Design,” Lawrence Livermore National Laboratory, Livermore, CA, UCRL-ID-150702.

Schneberk, Dan, Jessie Jackson and Harry Martz (2004), "Possible Laminographic and Tomosynthesis applications for Wolter Microscope Scan Geometries," Lawrence Livermore National Laboratory, Livermore, CA, UCRL-TR207196. 


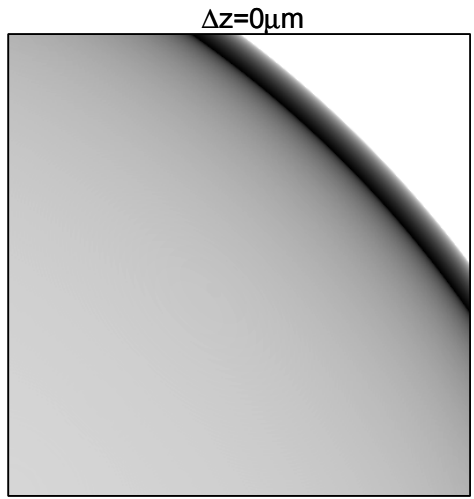

$\Delta \mathrm{z}=10 \mu \mathrm{m}$

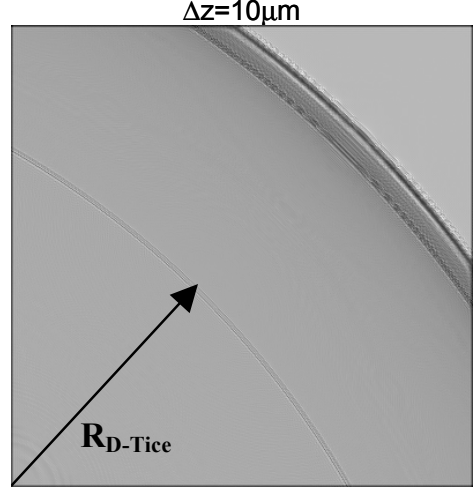

Perfect optic assumed at this stage

100 illumination points, annular fill of $\sigma=0.8$

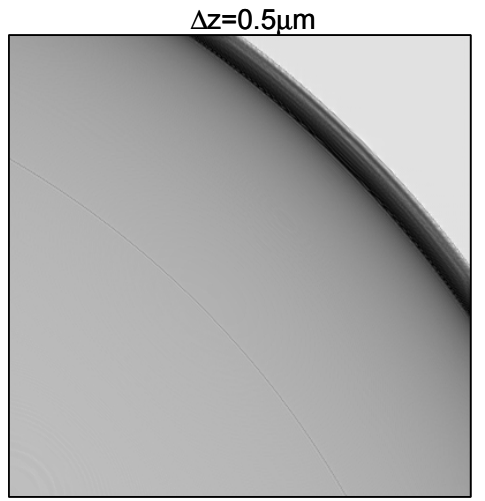

$\Delta \mathrm{z}=20 \mu \mathrm{m}$

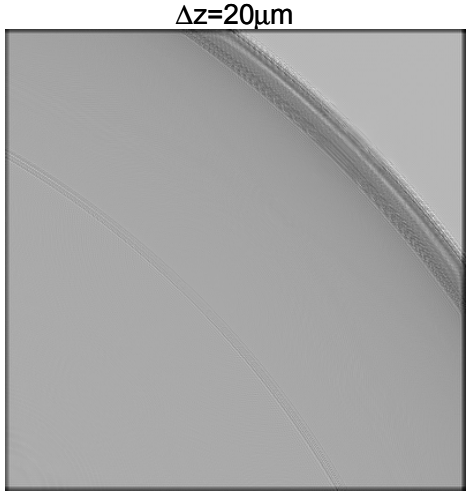

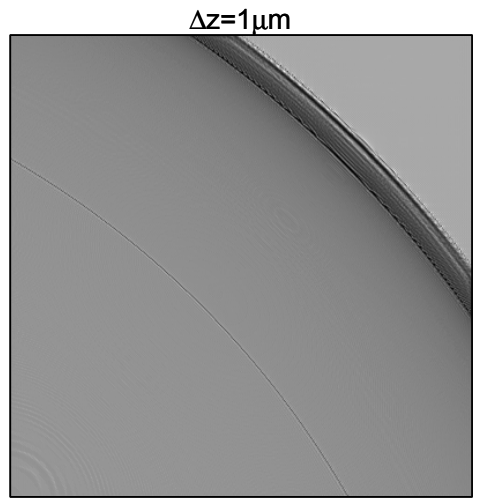

$\Delta \mathrm{z}=50 \mu \mathrm{m}$

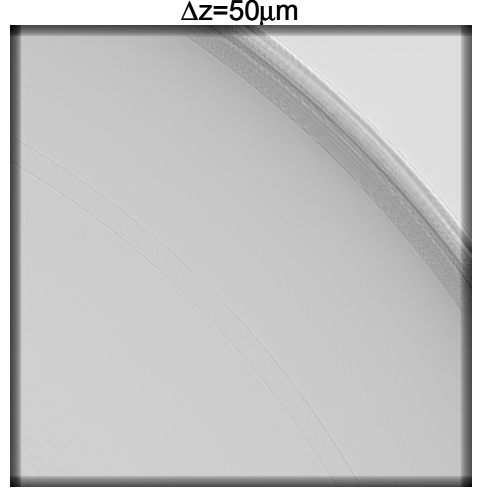

Figure 1. A perfect Wolter optic microscope simulation of a D-T ice layer inside a Be capsule. Exit- to image-plane distances are labeled as $\Delta \mathrm{z}$. The D-T ice gas layer is discernable for $\Delta \mathrm{z}$ of $>=0.5 \mathrm{um}$. 


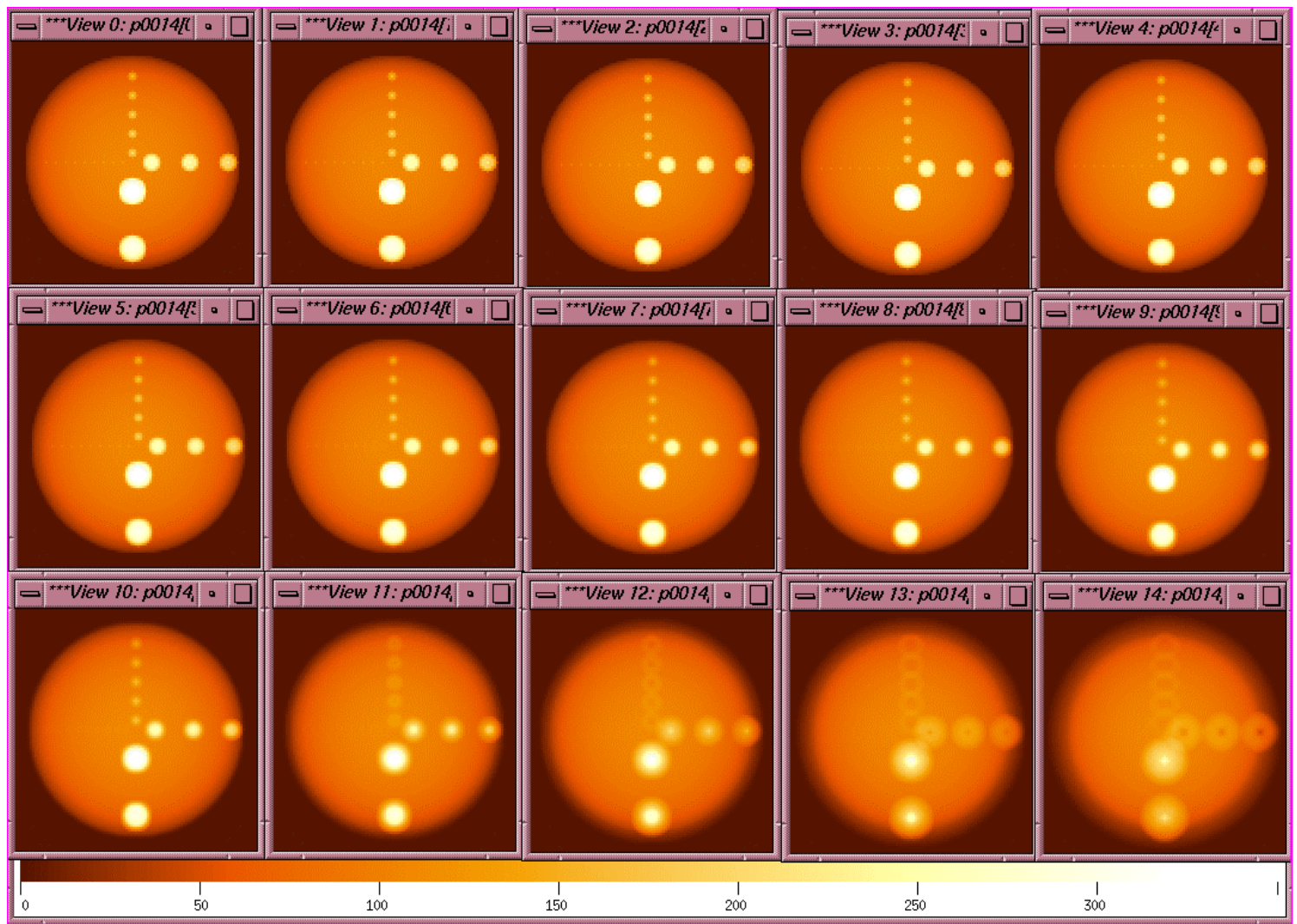

Figure 2 Simulated images of a 45 -um diameter spherical object with a number of spherical ( 0.5 -not observed, 2.5, 4.5, and 6.5-um diameter) inclusions on the center plane of the sphere. Each inclusion is 180 times more attenuating than the surrounding sphere. The first image has the center plane of the spherical object on the focal plane of the instrument. The succeeding images are the results of translations of the object toward the camera along the instrument axis. Images 2-9 are each $0.5 \mathrm{um}$ steps further from the focal plane ( $0.5 \mathrm{um}$ to $4.5 \mathrm{um})$. The last five images are at $5,10,15,20,25 \mathrm{um}$ distance from the focal plane.

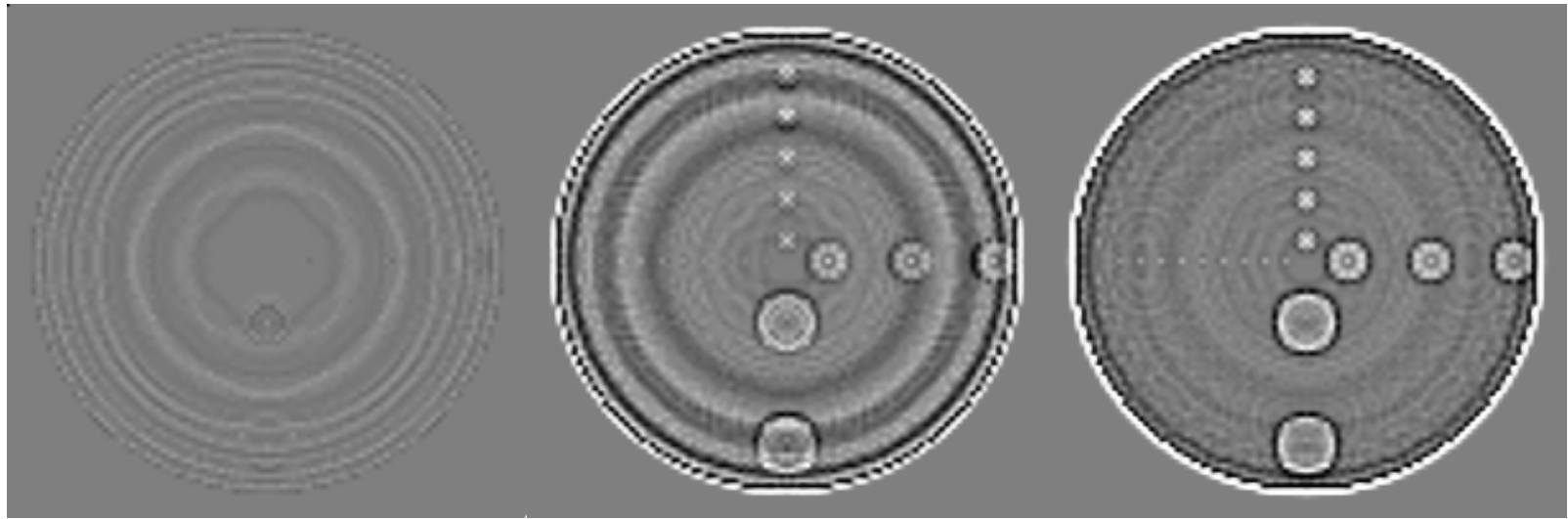

Difference of $0 \& 0.5$ um

Difference of $0 \& 2.5$ um

Difference of $0 \& 5$ um

Figure 3 Difference images of mid-plane focus, 0 um, to other translated views as labeled for the 45 -um diameter simulated spherical object shown in Figure 2. Note that the 0.5 um inclusions are revealed in the $0 \& 2.5$ um and $0 \&$ 5um difference images. 


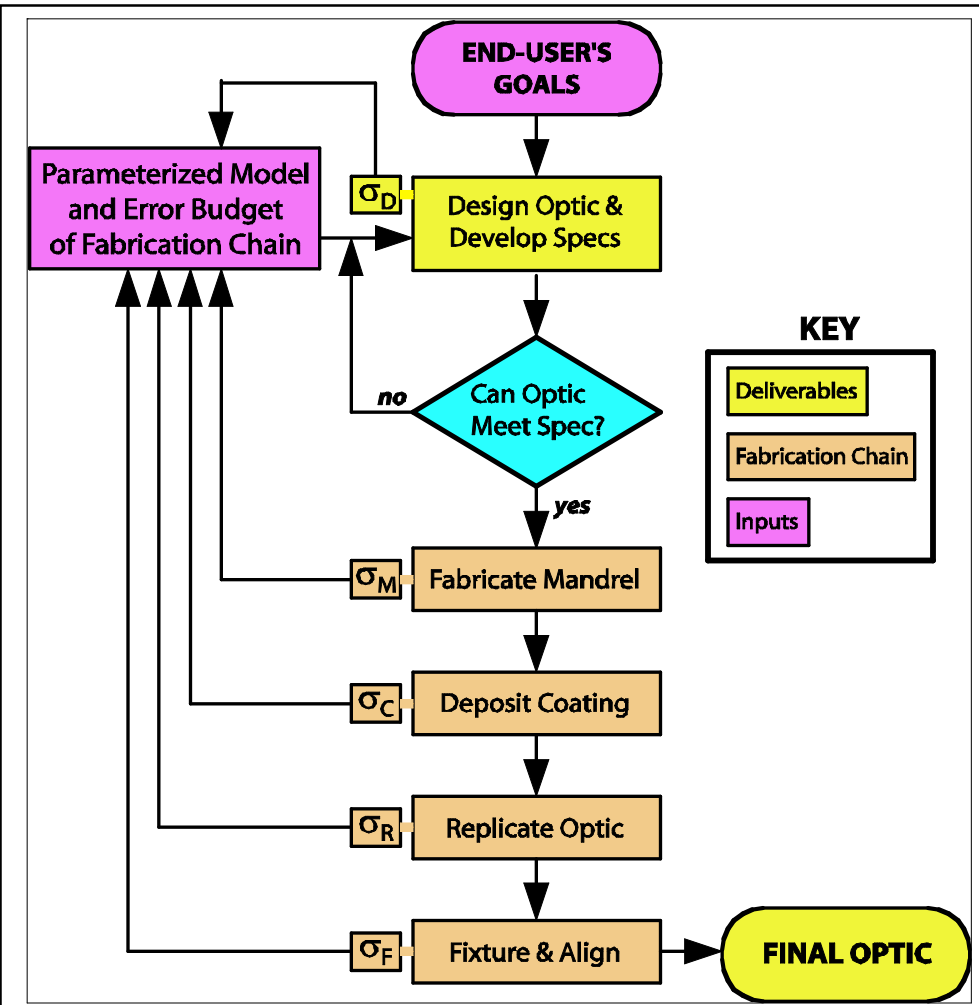

Figure 4: Replicated x-ray optic fabrication process flowchart

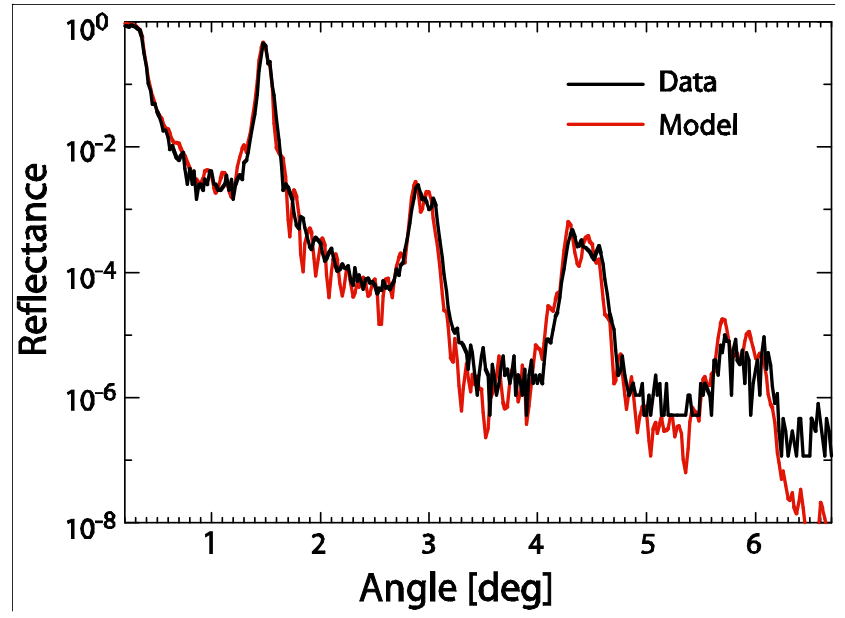

Figure 5: Measured reflectivity of the multilayer coating as a function of incident angle. 